\title{
LOAD-SETTLEMENT BEHAVIOUR OF MODEL PILE GROUPS IN SAND UNDER VERTICAL LOAD
}

\author{
Mauricio Martines SALES ${ }^{\mathrm{a}}$, Monica PREZZI ${ }^{\mathrm{b}}$, Rodrigo SALGADO ${ }^{\mathrm{b}}$, \\ Yoon Seok $\mathrm{CHOI}^{\mathrm{c}}$, Jintae $\mathrm{LEE}^{\mathrm{d}}$ \\ ${ }^{a}$ School of Civil and Environmental Engineering, Federal University of Goias, Goiania, 74605-220, Brazil \\ ${ }^{b}$ Lyles School of Civil Engineering, Purdue University, West Lafayette, IN 47907, USA \\ ${ }^{c}$ Fugro Consultants, Inc., 6100 Hillcroft, Houston, TX 77081, USA \\ ${ }^{d}$ Washington State Department of Ecology, Olympia, WA 98504, USA
}

Received 25 May 2017; accepted 15 Oct 2017

\begin{abstract}
Model pile load testing is effective to study the load-settlement behaviour of pile foundations given the controlled environment in which the testing is done. This paper reports a testing program in a large calibration chamber involving individual piles and pile groups installed in sand samples of three different densities. Tests on both nondisplacement and driven piles are evaluated to assess the influence of the pile installation process on pile load-settlement response. A method is proposed to predict the load-settlement response of a pile group based on the response of a single pile. The method is shown to produce estimates that are in good agreement with measurements. The influence of pile group configuration, pile spacing, soil density and method of pile installation is discussed.
\end{abstract}

Keywords: model piles, pile group, load-settlement analysis, driven piles, vertical load.

\section{Introduction}

Estimation of the load-settlement response of a pile group remains a challenge. The pile installation process, pile spacing and the role played by the cap over the piles, with or without ground contact, are some of the factors whose influence on the pile group response need to be better understood. Research based on full-scale pile group load tests (Garg 1979; Liu et al. 1985; Bai et al. 2006; Dai et al. 2012) is still infrequent because of the inherent difficulties of using a large and expensive load-reaction frame system. Consequently, model pile group tests are increasingly used. Some studies have been performed using centrifuge tests (Millan et al. 1987; Horikoshi, Randolph 1996; Conte et al. 2003; Nguyen et al. 2013), others in the laboratory using large chambers under normal gravity (1 g) conditions (Whitaker 1960; Cooke 1986; Lee, Chung 2005; Aoyama et al. 2016; Salgado et al. 2017).

Model pile load tests performed in large chambers play an important role in the understanding of the underlying physical process in soil-pile interaction and in determining the key factors controlling the load-settlement response of piles. Model tests are advantageous because they allow for good control of the initial soil conditions and repeatability of the pile installation process. Recent research using piles in calibration chamber have addressed the effect on pile stiffness of shaft-soil interface stresses, particle crushing, effect of surface roughness, shear band (Yang et al. 2010; Tsuha et al. 2012; Jardine et al. 2013a, 2013b; Tehrani et al. 2016). Advances on the use of particle image velocimetry (PIV) and digital image correlation (DIC) are allowing a better understanding of these factors (Arshad et al. 2014). However, smallscale laboratory model tests do not perfectly represent real tests owing to boundary and scale effects and, in the case of $1 \mathrm{~g}$ tests, stress level along the piles. Some researchers (Parkin et al. 1980; Schnaid, Houlsby 1991; Salgado et al. 1998) have noted that certain limit ratios of chamber diameter to pile diameter and of pile diameter to representative soil-particle size should be considered in planning calibration chamber experiments. Most authors advocate that a chamber diameter-to-pile diameter ratio of at least 50 should be used. Salgado et al. (1998) showed that this ratio could be even higher for very dense sands.

To study the complexities of pile and pile group behaviour, researchers at Purdue University built a large chamber and a pluviation system for laboratory model pile testing (Lee 2008; Choi 2012; Lee et al. 2013; Choi

Corresponding author: Mauricio Martines Sales

E-mail: sales.mauricio@gmail.com 
Table 1. Engineering properties of F-55 sand

\begin{tabular}{lcc}
\hline \multicolumn{1}{c}{ Geotechnical property } & Value & Method \\
\hline Specific gravity $\left(G_{s}\right)$ & 2.65 & \\
\hline Effective particle size $\left(D_{10}\right)$ & $0.15 \mathrm{~mm}$ & \\
\hline Mean particle size $\left(D_{50}\right)$ & $0.23 \mathrm{~mm}$ & \\
\hline Coefficient of uniformity $\left(C_{u}\right)$ & 1.67 & ASTM D 4253-00 (2000) \\
\hline Coefficient of curvature $\left(C_{c}\right)$ & 1.07 & ASTM D 4254-00 (2000) \\
\hline Max. void ratio $\left(e_{\max }\right)$ & 0.78 & CKC triaxial test \\
\hline Min. void ratio $\left(e_{\min }\right)$ & 0.47 & \\
\hline Critical-state friction angle $\left(\phi_{c}\right)$ & $33^{\circ}$ & \\
\hline Grain shape description & Rounded to subrounded & \\
\hline
\end{tabular}

et al. 2017). This equipment was used to obtain the results presented in this paper. The main goals of this paper are (a) to present the results of a set of 5model single pile and 11 model pile group tests under vertical load that were performed in sand samples and (b) to evaluate the ability to predict driven pile group response based on knowledge of the response of a single pile load response.

\section{Test preparation}

\subsection{Soil preparation}

The soil used in all the model pile load tests was a fine uniform silica sand (F-55 sand) with particle size ranging from $0.1 \mathrm{~mm}$ to $0.4 \mathrm{~mm}$ and mean sand particle diameter $D_{50}$ of $0.23 \mathrm{~mm}$. Considering that the diameter of all piles was $30 \mathrm{~mm}$, the ratio of the model pile diameter to the average sand particle diameter was 130 . This ratio is greater than the minimum value suggested by many authors to minimise internal scale effects: 50 by Vipulanandan et al. (1989); 80 by Peterson (1988) and 100 by Loukidis and Salgado (2009). The ratio of 130 also ex- ceeds the ratio of at least 20 , suggested as the minimum required value to eliminate the scale effects on base resistance by Salgado (2012). F-55 sand is finer than Ottawa ASTM standard sand (ASTM C778-06 2006). The sand in the experiment reported here was dry; and some of its properties are summarised in Table 1.

The soil chamber used in this research has an internal diameter of 2,000 $\mathrm{mm}$ and a height of $1,600 \mathrm{~mm}$. Figure 1a shows a lateral chamber view and the steel beam of the reaction system used to perform the tests. The chamber-to-pile diameter ratio is approximately 67 , and the boundary effects, as discussed previously, are expected to be very small for these tests.

The method selected to prepare sand samples of various densities in the chamber was the stationary pluviation technique, which consists of raining the sand from a certain fall height while maintaining the flow rate. The pluviator consists of a steel sand container, an acrylic plate, and two layers of diffuser sieves. A view of the sand pluviator used in sand preparation is presented in Figure 1b. The bottom steel plate of the sand container

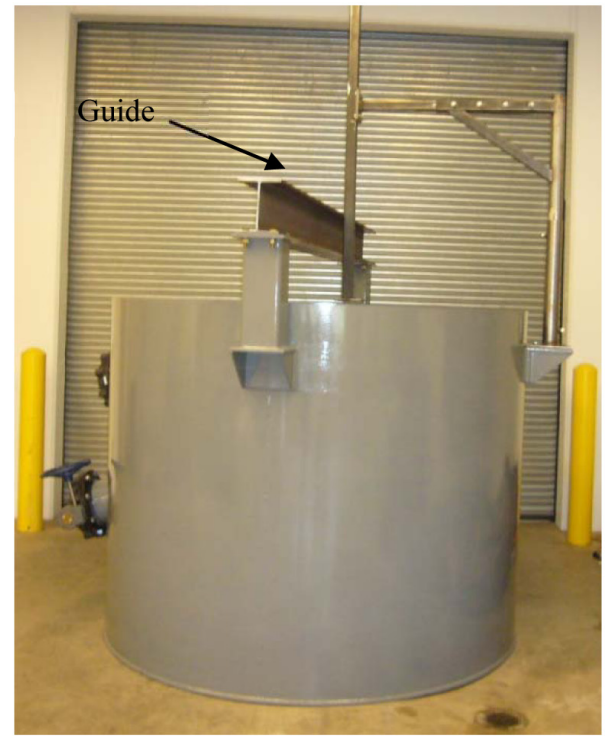

(a)

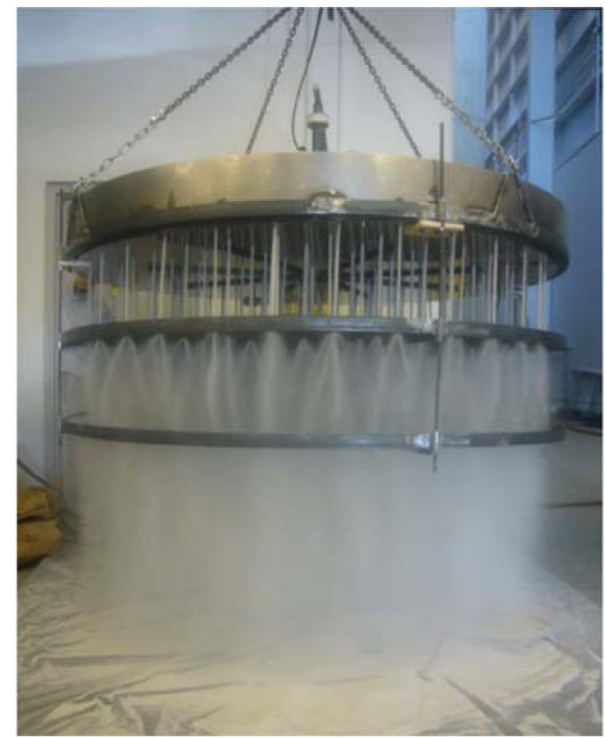

(b)

Fig. 1. Soil preparation for model pile tests: (a) Chamber lateral view, (b) sand pluviation process 

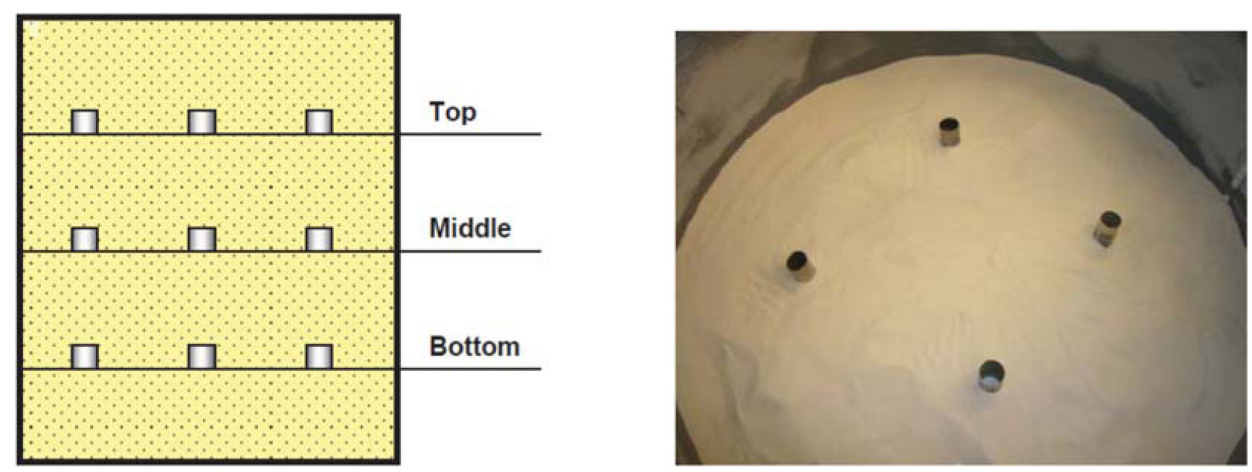

Fig. 2. Molds used to control the sand relative density

and the acrylic plate have the same pattern of circular holes (diameter $=10 \mathrm{~mm}$ ). When the holes are aligned, sand pluviation starts. Two layers of diffuser sieves with different opening sizes of $3.35 \mathrm{~mm}$ (No. 6 in the first layer) and $1.18 \mathrm{~mm}$ (No. 16 in the second layer) were used. The function of the diffuser sieves is to ensure that the sand is evenly and uniformly distributed inside the soil chamber. By adjusting the sand discharge rate (choosing the sieve opening size) and drop height, a wide range of sand densities can be achieved. The sand pluviator was placed above the chamber during soil preparation and moved out before the tests with the help of a hoist crane.

The optimal combination of sieve opening size and drop height was determined after some trial tests. The objective was to produce loose, medium dense and dense sand samples with relative densities of approximately $40 \%, 60 \%$ and $90 \%$, respectively. The relative density was checked every time the chamber was filled up to three different levels, using four molds at each level, as shown in Figure 2. The total weight used to fill up the chamber was also measured and was used to check the average relative density in each test. The test results indicated average relative density values of $91.1 \pm 2.1 \%$, $59.3 \pm 2.3 \%$, and $38.3 \pm 3.0 \%$ for dense, medium dense, and loose sand, respectively.

Tests in calibration chambers are often done with a surcharge applied on top of the soil sample to simulate

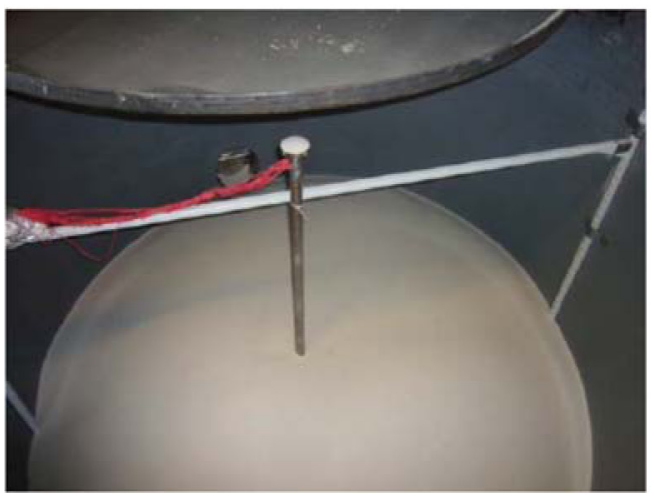

(a) the stress level found at depth (Salgado et al. 1998; Paik, Salgado 2004; Yang et al. 2010; Jardine et al. 2013a, 2013b; Arshad et al. 2014). It is important to stress that, in such cases, the tests are simulating the section of a pile or pile group near the base of the pile, and not the entire pile. In the present set of model pile load tests, no surcharge was applied on the sample in order to obtain a behavior that, except for the difference in stress level, is reflectrive of the behavior of an entire pile group.

\subsection{Piles and pile installation}

Four closed-ended-pipe model piles were fabricated for this research. The outer diameter, wall thickness, and length of the model piles were $30 \mathrm{~mm}, 2 \mathrm{~mm}$, and $1200 \mathrm{~mm}$, respectively. The piles were instrumented with electrical resistance strain gauges at six different levels along the shaft and a load cell at the pile base. There was a small gap $(3 \mathrm{~mm})$, sealed with silicone, to separate the pile base from the shaft and to guarantee correct measurements of base and shaft loads.

Two different processes were used to install the piles: pre-installation (positioning of the pile before the soil sample is fully prepared; it is used to simulate the installation of ideal non-displacement piles) and driving. Pre-installation involved first pluviating a sand bed of approximately $400 \mathrm{~mm}$ in height, positioning the model pile with its base resting on the sand bed (Fig. 3a), and

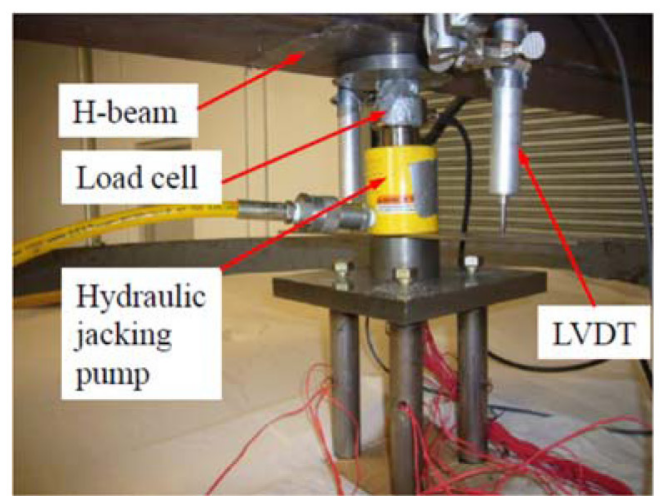

(b)

Fig. 3. Pile group test - preparation: (a) Pile installation; (b) 4-pile group test 
Table 2. Pile drivability

\begin{tabular}{lcccc}
\hline \multicolumn{1}{c}{ Sand density } & Pile driving order & Penetration $(\mathrm{mm})$ & Total blows & Average set $(\mathrm{mm} / \mathrm{blow})$ \\
\hline \multirow{3}{*}{ Dense } & $1^{\text {st }}$ & 916 & 132 & 6.9 \\
$\left(D_{R}=91 \%\right)$ & $2^{\text {nd }}$ & 907 & 126 & 7.2 \\
& $3^{\text {rd }}$ & 950 & 125 & 7.6 \\
\hline & $4^{\text {th }}$ & 963 & 131 & 7.4 \\
Medium dense & $1^{\text {st }}$ & 930 & 57 & 16.3 \\
$\left(D_{R}=59 \%\right)$ & $2^{\text {nd }}$ & 950 & 84 & 11.3 \\
& $3^{\text {rd }}$ & 939 & 110 & 8.5 \\
& $4^{\text {th }}$ & 946 & 121 & 7.8 \\
Loose & $1^{\text {st }}$ & 983 & 36 & 27.3 \\
$\left(D_{R}=38 \%\right)$ & $2^{\text {nd }}$ & 960 & 39 & 24.6 \\
& $3^{\text {rd }}$ & 961 & 47 & 20.4 \\
\hline
\end{tabular}

continuing the pluviation of the sand until completion of a sample with a total height of $1400 \mathrm{~mm}$ (short of the top of the chamber by $200 \mathrm{~mm}$ ). Two tests were performed on pre-installed piles: one in medium dense sand and the other in dense sand.

Piles were driven into the sand sample using a guide rod (shown in Fig. 1a) and a steel hammer. The hammer weight and drop height were $3 \mathrm{kgf}(29.4 \mathrm{~N})$ and $1 \mathrm{~m}$, respectively, which resulted in a theoretical driving energy of $29.4 \mathrm{Nm}(\mathrm{J})$. Figure $3 \mathrm{~b}$ shows a 4-driven model pile group ready for a vertical load test. Table 2 compares the number of blows required to drive each model pile in the 4-pile group in sand samples with three different relative densities. For loose and medium dense sands, an increasing number of blows is required for piles driven later in the group installation process; however, for dense sand, the number of blows required to drive the piles was essentially the same for all piles. For the loose and medium dense sand, the initial void ratio was high enough that densification at the location of neighboring piles caused by driving of earlier piles resulted in greater driving resistance. For dense sand, this was not true; instead, it was marginally easier to drive piles later in the sequence.

\section{Pile group testing program}

Table 3 presents the results of the 16 model pile load tests performed in sand with different densities. Axial load tests were first performed on a single-model pile and then on model pile groups. The non-displacement single pile tests were performed in medium dense $\left(D_{R}=59 \%\right)$ and dense $\left(D_{R}=91 \%\right)$ sands, and the driven single pile tests were performed in sand with three different densities $\left(D_{R}=38 \%, 59 \%\right.$, and $\left.91 \%\right)$.

All pile group configurations were composed of driven piles arranged in three different ways: 2piles; 3 piles in-line and 4piles in a square configuration; all at first with a typical center-to-center pile spacing of three diameters $(3 B)$. To investigate the effect of pile spacing, additional axial load tests were performed on $2 \times 2$ model pile groups in the medium dense sand using spacings of two $(2 B)$ and four $(4 B)$ pile diameters.
Axial load tests were performed in accordance with ASTM D 1143/D 1143 M-07 (2007). The load was applied by a hydraulic jack, and the loads were measured by a calibrated load cell $(25 \mathrm{kN}$ of capacity and $0.01 \mathrm{~N}$ of precision). The vertical displacements of the pile head in single pile load tests and the pile group cap were recorded by LVDTs with a precision of $0.0001 \mathrm{~mm}$. The static axial load was increased with load increments of approximately $0.3 \mathrm{kN}$ for dense and medium dense sands and $0.1 \mathrm{kN}$ for loose sands. All tests were performed up to displacements exceeding $20 \mathrm{~mm}$.

\section{Results}

\subsection{Single pile: nondisplacement $\boldsymbol{x}$ driven}

Figure 4 compares the results of the tests on non-displacement and driven single piles for sand samples with two different densities: medium dense $\left(D_{R}=59 \%\right)$ and dense $\left(D_{R}=91 \%\right)$. The greater the sand density, the higher the load capacity and pile stiffness for the same pile

Table 3. List of performed tests

\begin{tabular}{llcc}
\hline $\begin{array}{l}\text { Installation } \\
\text { process }\end{array}$ & Sand density & $\begin{array}{c}\text { Number } \\
\text { of piles }\end{array}$ & $\begin{array}{c}\text { Pile-to-pile } \\
\text { spacing }(\mathrm{x} B)\end{array}$ \\
\hline & Loose & 2 & - \\
& $D_{R}=38 \%$ & 3 & 3 \\
& & 4 & 3 \\
\cline { 2 - 4 } Driven Piles & Medium dense & 1 & - \\
& $D_{R}=59 \%$ & 2 & 3 \\
& & 4 & 3 \\
& & 4 & 2 \\
\cline { 2 - 4 } & & 4 & 3 \\
& Dense & 1 & - \\
& $D_{R}=91 \%$ & 2 & 3 \\
& & 3 & 3 \\
\hline \multirow{2}{*}{ Nondisplace- } & Medium dense & 1 & - \\
\cline { 2 - 4 } ment Piles & $D_{R}=59 \%$ & 1 & - \\
\hline & Dense $D_{R}=91 \%$ & & 3 \\
\hline
\end{tabular}




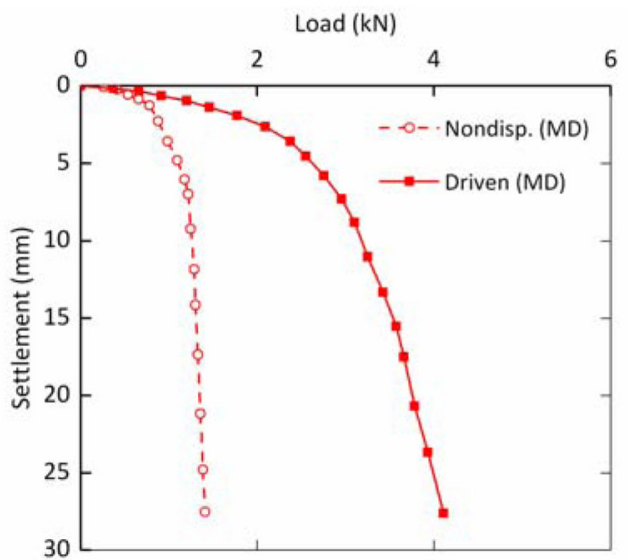

(a)

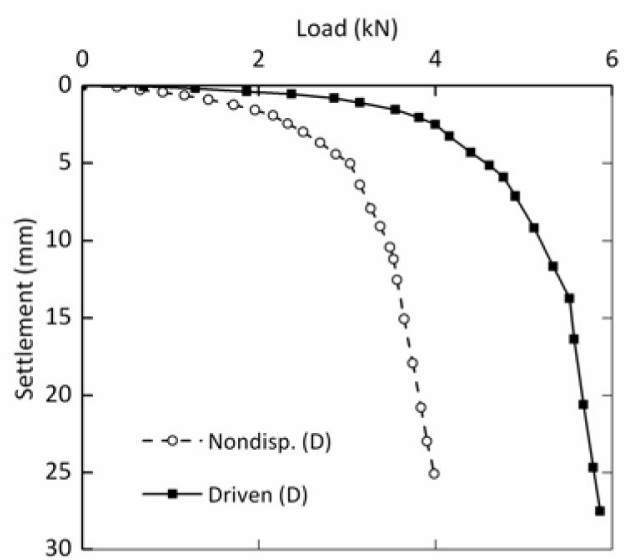

(b)

Fig. 4. Comparison of non-displacement vs. driven pile tests: (a) Medium dense sand; (b) dense sand

installation process. Considering the ultimate axial load as the load corresponding to a vertical settlement of $10 \%$ of the pile diameter $(0.1 B=3 \mathrm{~mm})$, the ultimate load of the driven piles was observed to be greater than that of the corresponding non-displacement piles $(2.25 \mathrm{kN}$ versus $0.93 \mathrm{kN}$, an increase of $142 \%$, for medium dense sand; $4.12 \mathrm{kN}$ versus $2.52 \mathrm{kN}$, an increase of $63 \%$, for dense sand).

Table 4 shows that both the shaft and base load capacities are greater for driven piles. The difference in base resistance was greater in the medium dense sand test (densification below the base playing an important role), but the shaft load difference was greater in dense sand.

Figure 5 compares the load-settlement response of driven single model piles for the three different sand densities $\left(D_{R}=38,59\right.$, and $\left.91 \%\right)$ considered. The ultimate loads are $0.93 \mathrm{kN}, 2.25 \mathrm{kN}$, and $4.12 \mathrm{kN}$ for loose, medium dense and dense sand, respectively.

Table 4. Ultimate, shaft, and base loads for single model piles in sand

\begin{tabular}{lcccc}
\hline & \multicolumn{2}{c}{ Medium dense } & \multicolumn{2}{c}{ Dense } \\
\cline { 2 - 5 } $\begin{array}{l}\text { Loads } \\
(\mathrm{kN})\end{array}$ & $\begin{array}{c}\text { Non-dis- } \\
\text { placement }\end{array}$ & Driven & $\begin{array}{c}\text { Non-dis- } \\
\text { placement }\end{array}$ & Driven \\
\hline$Q_{\text {base }}$ & $0.55(59 \%)$ & $1.47(67 \%)$ & $1.64(65 \%)$ & $2.19(53 \%)$ \\
$Q_{\text {shaft }}$ & $0.38(41 \%)$ & $0.73(33 \%)$ & $0.89(35 \%)$ & $1.93(47 \%)$ \\
$Q_{\text {total }}$ & 0.93 & 2.25 & 2.52 & 4.12 \\
\hline
\end{tabular}

\subsection{Driven pile groups}

Axial load tests were performed with three different pile arrangements of model pile groups: $1 \times 2,1 \times 3$ (in line), and $2 \times 2$. All of these groups had center-to-center pile spacing of three pile diameters $(S=3 B)$. Figure 6 shows the results of nine model pile group tests with the different group configurations and soil density values considered. The greater the number of piles and the soil density, the greater the load capacity and stiffness of all pile groups.

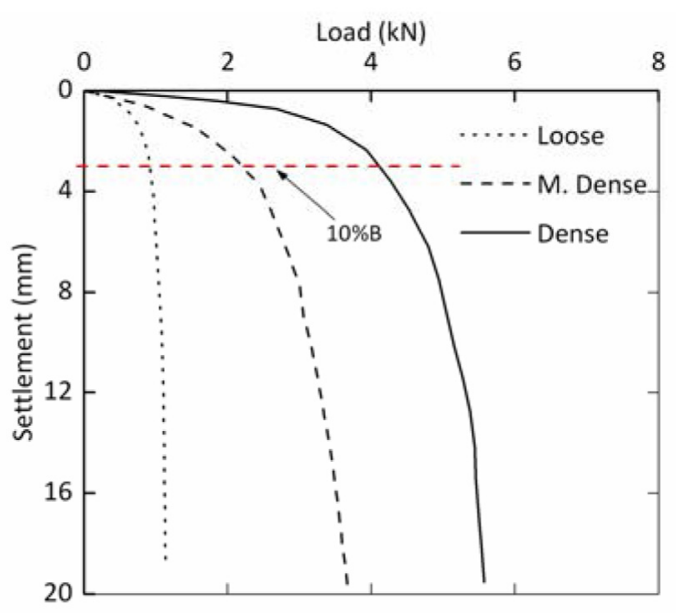

Fig. 5. Load versus settlement response of single driven piles from load tests for different sand relative densities

\subsection{Pile groups with different pile spacing}

To investigate the effect of pile spacing, pile groups with $2 \times 2$ configurations were tested with $2 B$ and $4 B$ spacing, in addition to the $3 B$ spacing, in medium dense sand.

Figure 7 presents the results of the three tests for 4-pile groups in medium dense sand for the three spacings considered as well as the results for the pile group tested in dense sand. A very marginal increase in the ultimate load capacity can be observed for $S=2 B$ when the tests of only medium dense sand are considered. Based on these results, it can be concluded that pile spacing has minimal effect on group capacity if the center-to-center pile spacing exceeds $2 B$. The effect of density is clear: all tests in medium dense sand had a considerably lower load capacity compared with the results obtained for dense sand. This shows that, despite the fact that densification of soil in the vicinity of the piles occurs, the gains in capacity are nowhere near as large as needed to match the capacity that is available from piles installed in sand initially very dense. 


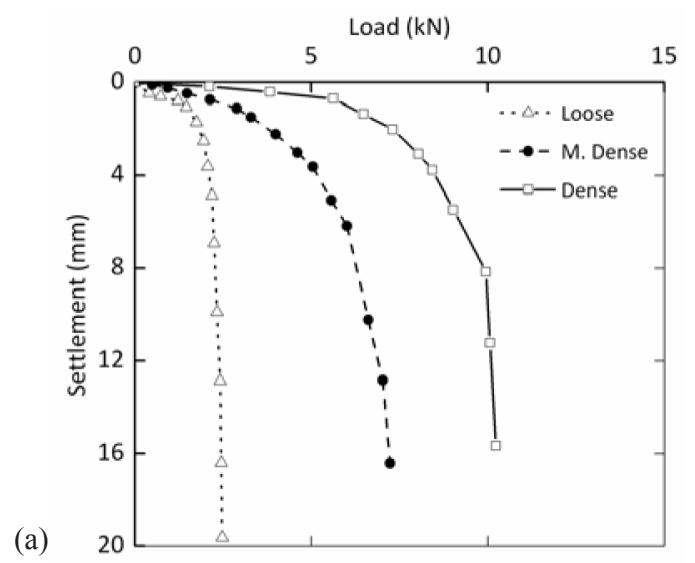

(b)

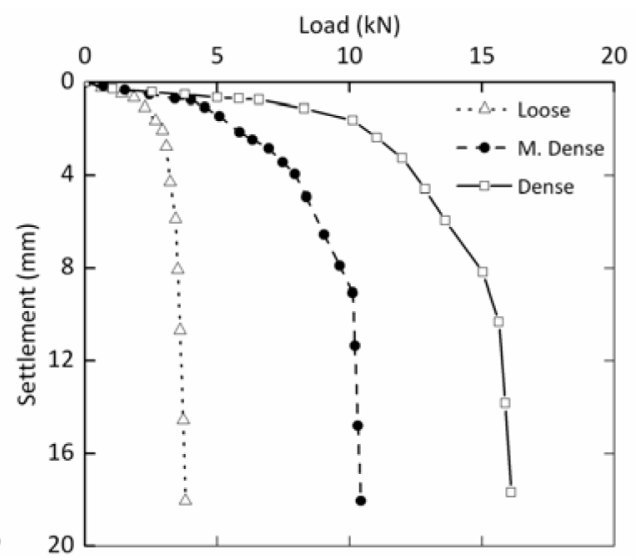

(c)

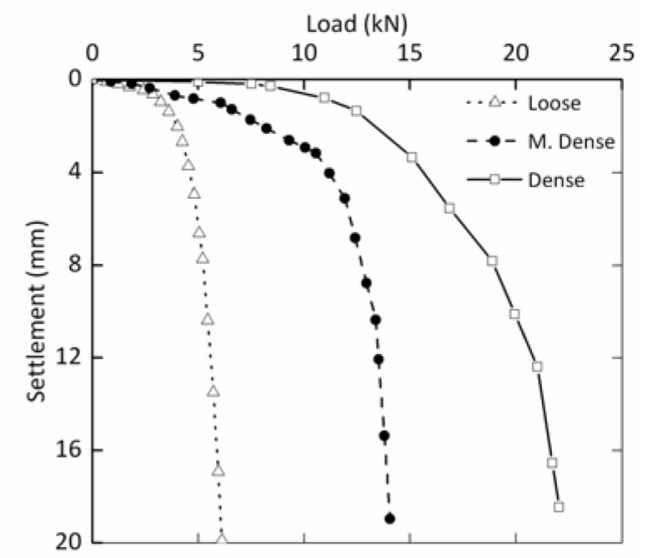

Fig. 6. Pile group tests with driven piles for $S / B=3$ : (a) 2-pile group; (b) 3-pile group; (c) 4-pile group

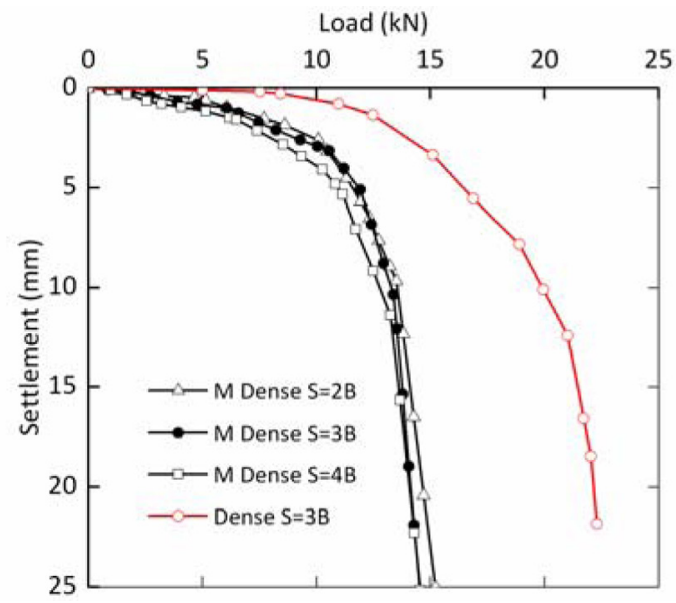

Fig. 7. Comparison of 4-pile group tests for medium dense sand vs. dense sand

\section{Analysis and discussion}

\subsection{Group efficiency in terms of load capacity}

Early methods for estimating pile group efficiency were often based on geometry. Empirical equations, as the Converse-Labarre formula, proposed approximations to calculate group efficiency considering only number of piles, group geometry, pile diameter, and spacing between piles. There is now consensus that group effect evaluation should consider both soil and pile characteristics. Some authors (El-Sharnouby, Novak 1990; Mylonakis, Gazetas 1998) prefer to express group efficiency $\eta$ as the ratio of pile group stiffness to the stiffness that the group would have if there were no interaction between the piles in the group and no changes in their individual response induced by the sequential installation of the piles:

$$
\eta=\frac{K_{g}}{n K_{1}}
$$

where $n$ is the number of piles in the group; and $K_{g}$ and $K_{1}$ are the pile group and single pile stiffnesses.

Poulos et al. (2001), in a similar way as Kezdi (1957), suggested calculating the group efficiency $\eta$ as the ratio of the ultimate load capacity of the pile group to the sum of all ultimate load capacities of the piles that compose the group:

$$
\eta=\frac{Q_{u g}}{\sum Q_{u}},
$$

where $Q_{u g}$ and $Q_{u}$ are the ultimate load capacity of the pile group and single pile, respectively, defined as the load corresponding to a settlement equal to $10 \%$ of the pile diameter. 
If the ultimate load capacity and the stiffness of the pile group are taken at the same settlement level, the definitions given by Eqns (1) and (2) are the same. The group efficiency for a settlement $w_{10 \%}$ equal to $10 \%$ of the pile diameter is given by:

$$
\eta=\frac{K_{g}}{n K_{1}}=\frac{\frac{Q_{u g}}{w_{10 \%}}}{n \frac{Q_{u}}{w_{10 \%}}}=\frac{Q_{u g}}{n Q_{u}} .
$$

O’Neill (1983) performed tests on model pile groups in sand. The results indicated that the group efficiency always exceeds unity in loose sand and that its highest value was observed for a pile spacing of two pile diameters. O’Neill (1983) also reported that efficiency increases with increasing number of piles in the group. Poulos et al. (2001) and Viggiani et al. (2012) suggested that the group efficiency may be considerably greater than 1 for driven piles in loose to medium dense sand and that it should be taken as 1 for design purposes. In dense sand, the efficiency was observed to be either greater or less than unity (O’Neill 1983).

Figure 8 shows the group efficiency $\eta$ calculated using Eqn (3) for all model pile group tests. For loose-tomedium dense sand tests, $\eta$ is greater than 1 . The group efficiency increases with increasing number of piles in each group and was higher for loose sand tests than for medium dense sand tests. However, the opposite was observed for the model pile tests in dense sand. The 4-pile group test had lower group efficiency than those of the 2- and 3-pile groups. The initial void ratio of the sand samples and sand dilatancy were primarily responsible for the observed group efficiency results. Notably, these results suggest that the value of " 1 " for group efficiency may not be conservative for pile groups in dense sands.

\subsection{Driven piles - response of single pile versus that of last pile driven in group}

Figure 9 compares the load-settlement response of a single model pile with those measured for the instrumented

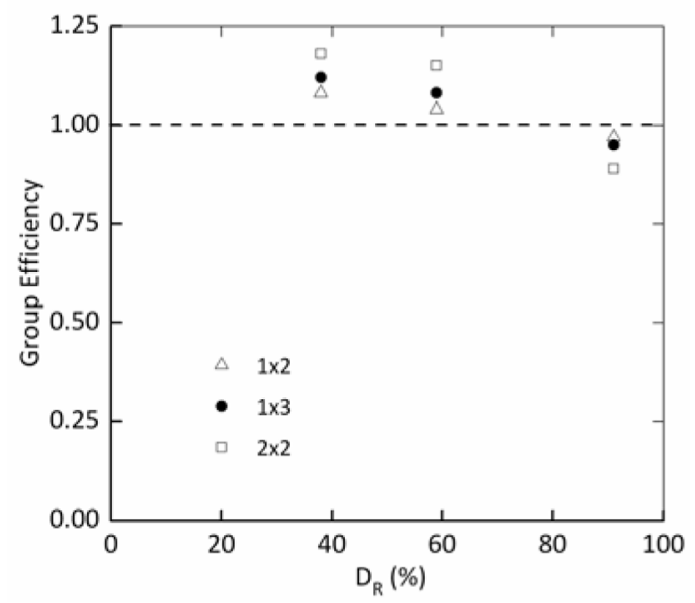

Fig. 8. Load-capacity group efficiency of driven pile groups model pile driven last in each group for all sand densities (from this instrumented model pile it was possible to obtain the total load applied to it from the strain gauges located outside the sand sample). Note that the model piles in a group underwent the same settlement for each load applied because a rigid cap was used in all the tests. Considering all the load-settlement curves for each sand density, it can be observed that the ultimate load capacity of the individual model piles in each of the three groups is greater than that of the single model pile for the tests performed in loose sand samples. The increases in ultimate load capacity were smaller for medium dense

(a)

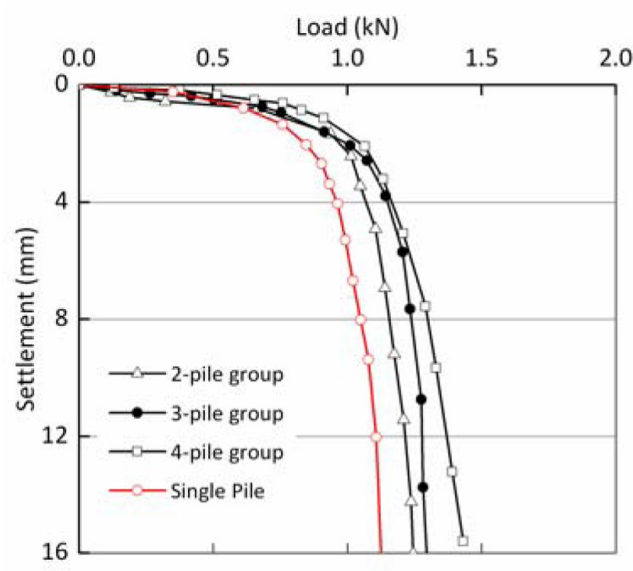

(b)

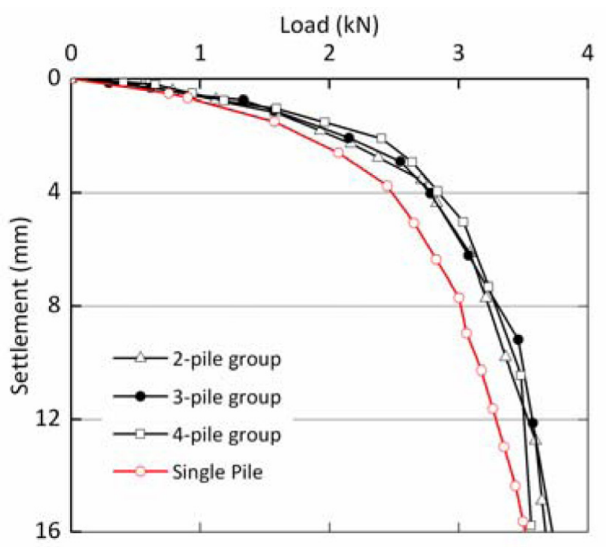

(c)

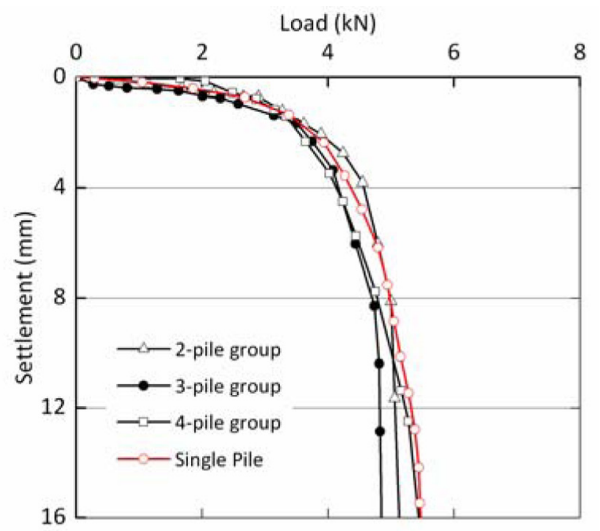

Fig. 9. Comparison of the capacity of a single model pile with those of the last model pile driven in each group $(S / B=3)$ : (a) loose sand; (b) medium dense sand; (c) dense sand 
sand, while all piles have very similar response in dense sands.

A nonlinear equation can be fit to the load-settlement response of the single model pile measured in the calibration chamber tests. The nonlinear degradation of the pile stiffness $K_{p}$ can be expressed as:

$$
K_{p}=K_{i}\left(1-R F\left(\frac{Q}{Q_{u}}\right)\right),
$$

where $Q_{u}$ is the ultimate load (load at a settlement $w_{10 \%}$ equal to $10 \%$ of the pile diameter); $K_{i}$ is the initial pile

(a)

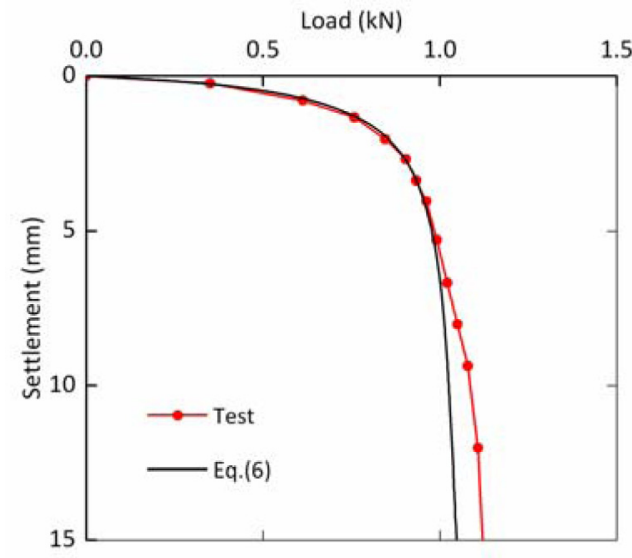

(b)

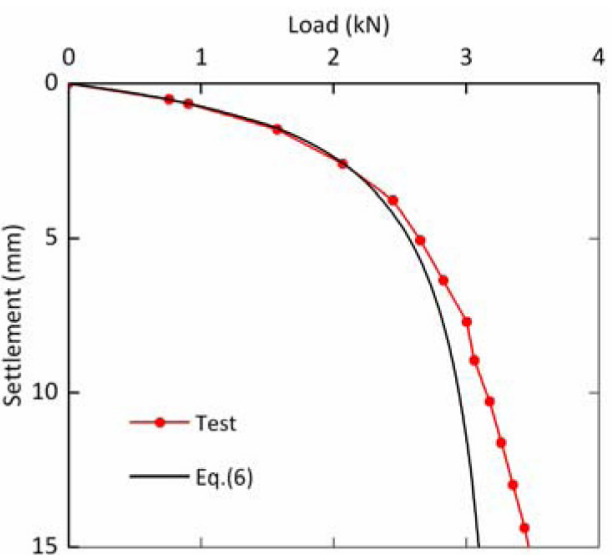

(c)

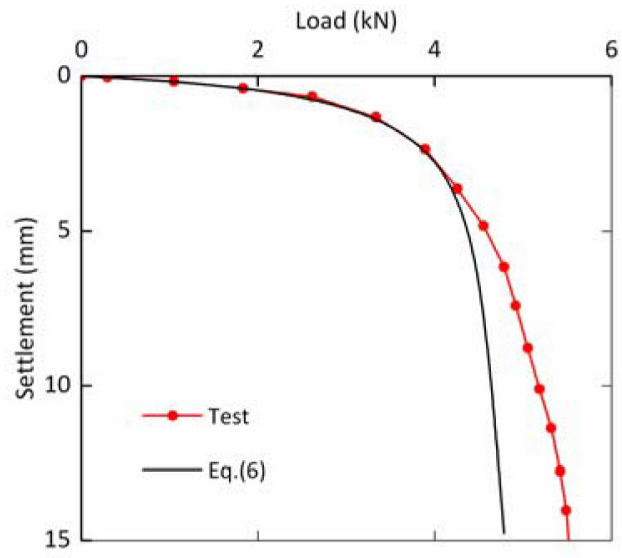

Fig. 10. Measured single pile axial load response and predicted from Eqn (6), $(S / B=3)$ : (a) loose sand, (b) medium dense sand, (c) dense sand stiffness, obtained through a linear regression analyses of the load-settlement data for $\mathrm{w}$ ranging from 0 to $2.5 \%$; $K_{f}$ is the final pile stiffness, defined as the ratio of the ultimate load to $w_{10 \%}$; and $R F$ is the hyperbolic factor, which is given by:

$$
R F=\left(\frac{K_{i}-K_{f}}{K_{i}}\right) .
$$

Once the parameters in Eqn (4) are known, the pile settlement corresponding to an axial load $Q$ can be calculated from:

$$
w=Q / K_{p} .
$$

Table 5 summarises the values of $R F$ obtained using Eqns (4) and (5) for single model pile tests in all sand densities, and Figure 10 has both the measured loadsettlement curves and the corresponding curves obtained using Eqn (6). The initial pile stiffness was similar for both tests in loose and medium dense sand, as shown in Table 5, but it was higher for the model pile test in dense sand. The hyperbolic factor $R F$ is in the $0.67-0.85$ range.

Table 5. Back-calculated parameters in Eqn (4) for all sand densities

\begin{tabular}{l|c|c|c}
\hline \multicolumn{1}{c|}{ Sand } & $Q_{u}(\mathrm{kN})$ & $K_{i}(\mathrm{kN} / \mathrm{m})$ & $R F$ \\
\hline Loose & 0.93 & 2000 & 0.847 \\
\hline Medium dense & 2.25 & 2200 & 0.675 \\
\hline Dense & 4.12 & 7700 & 0.823 \\
\hline
\end{tabular}

\subsection{Method used for pile group response predictions}

The software used for pile group predictions was the latest version of GARP (Poulos 1994, 2001; Small, Poulos 2007; Sales et al. 2010; Russo et al. 2013). This software was developed to simulate pile foundations and pile rafts and is based on a hybrid approach that combines finite element analysis for the raft (or cap) and elastic theory to consider soil-pile interaction. GARP is capable of simulating nonlinear pile load-settlement response in non-homogeneous or layered soil profiles, and it also allows inputting maximum values of pile capacity in compression and tension and capping the stresses below the raft in both compression and uplift.

In the present analysis, the thick steel plate (Fig. 3b) that connected the model pile group was considered as a cap without contact with the sand sample. The soil elastic modulus $E_{s}$ was back-calculated from all the single model pile test data using the DEFPIG software (Poulos 1990). Considering that all soil samples were prepared with clean, uniform sand, a linear function was chosen to represent the increase of $E_{s}$ with depth (increasing from zero at the sand surface to a specific value at the bottom of the chamber). The $E_{s}$ profile for each of the sand densities tested was adjusted until the initial stiffness obtained from the settlement analysis using the DEFPIG software matched the values presented in Table 5. The values of $E_{s}$ resulting from this process are given in Table 6 . 
Table 6. Adjusted $E_{s}$ profile for each sand density

\begin{tabular}{l|c}
\hline \multicolumn{1}{c|}{ Sand } & $E_{S}(\mathrm{MPa})$ \\
\hline Loose & $6.00 z^{*}$ \\
Medium dense & $6.45 z$ \\
Dense & $26.78 z$ \\
\hline
\end{tabular}

${ }^{*} z$ is depth from sand surface in meters

Pile-pile interactions must be considered in all pile group analysis; this can be done following (Poulos 1968):

$$
\rho_{i}=\sum_{j=1}^{n} \rho_{j} \alpha_{i j}=\sum_{j=1}^{n} \frac{Q_{j}}{K_{j}} \alpha_{i j}
$$

where $\rho_{i}$ and $\rho_{j}$ are the settlement of the $i$-pile and the $j$-pile, respectively; $\alpha_{i j}$ is the interaction factor between the $i$-pile and the $j$-pile; $Q_{j}$ is the load applied to the $j$-pile; and $K_{j}$ is the stiffness of the $j$-pile.

When piles are loaded up to an ultimate settlement level, the pile-pile interaction process represented by Eqn (7) is no longer accurate because of soil nonlinearity and localization of deformation in the shear band formed in the vicinity of the pile (Loukidis, Salgado 2008; Basu et al. 2011; Arshad et al. 2014; Arshad 2014). Mandolini and Viggiani (1997), based on previous work by Caputo and Viggiani (1984), Randolph (1994), Liang et al. (2014) and Zhang et al. (2015) suggested that the settlement of a pile in a group has two components: i) the settlement caused by the load carried by it considering stiffness degradation, and ii) the additional settlement caused to it by its neighboring piles, calculated considering the initial pile stiffness. Mathematically:

$$
\rho_{i}=\frac{Q_{i}}{K_{i_{N L}}}+\sum_{\frac{j=1}{j \neq i}}^{n} \frac{Q_{j}}{K_{j_{L}}} \alpha_{i j},
$$

where $K_{i N L}$ is the nonlinear secant stiffness of the $i^{\text {th }}$ pile at any loading stage, and $K_{j L}$ is the initial pile stiffness of all other neighboring piles.

In reality, pile group interaction factors depend on the type of pile, pile installation method, pile settlement level, sand density and stress level. Pile installation changes the state of the soil surrounding it. During loading of a pile, as indicated earlier, there is localization of stresses in the shear band to mobilise shaft capacity. Because of shear band formation, there is less interaction between piles in a group than is predicted using elasticity theory. Arshad et al. (2014) presented the results of model cone $(31.75 \mathrm{~mm}$ in diameter and $91.5 \mathrm{~mm}$ in length) penetration tests in sands with uniform density performed inside a half-circular steel chamber. Digital images of the cone penetrating into the sand samples were acquired during the entire penetration process, and the digital image correlation technique (DIC) was used to process these images to obtain the soil displacement field. Figure 11 shows a microscopic image of the sand-cone interface. A very thin, crushed particle band of thickness equal to approximately $2.5 D_{50}$ formed at the interface,

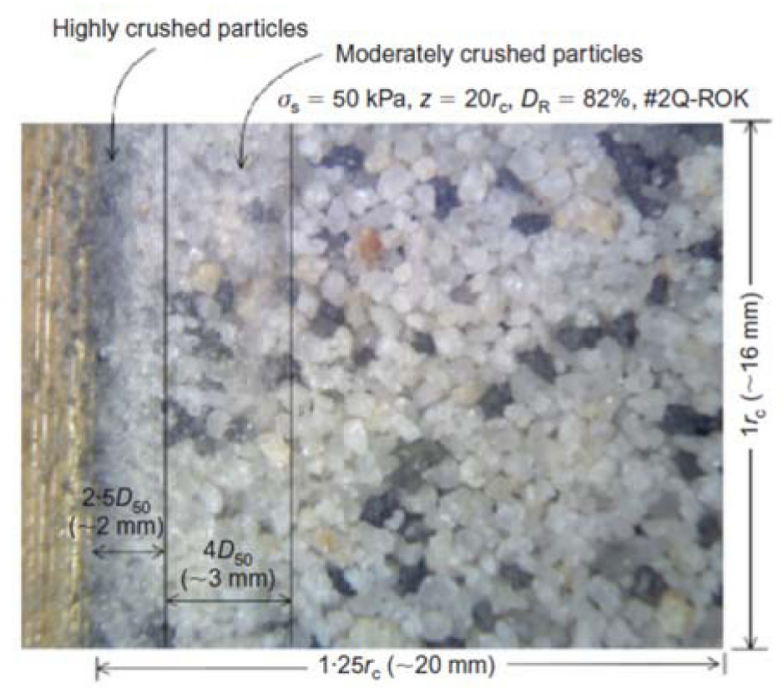

Fig. 11. Microscopic image of pile-soil interface of a model cone in uniform sand (Arshad et al. 2014)

and a neighboring $4 D_{50}$-thick band, consisting of moderately crushed sand particles, can also be observed. Besides the shear deformation localization along the pile shaft, Arshad et al. (2014) stated that crushing around the base, as the pile is pushed or driven into the soil, produces finer particles that more or less stay in place, forming a zone of crushed material that overlaps with the shear band; these two processes, localization and crushing, influence the displacement field observed around the shaft. Yang et al. (2010), based on CPT tests on Fontainebleau silica sand, suggested that the crushing process would occur for $q_{c}$ higher than $5 \mathrm{MPa}$. For the present sand preparation, three CPT tests were performed in the medium dense sand and four in the dense sand. As no surcharge was applied, an average, approximately linear increase of $q_{c}$ was noted changing from zero, at the sand surface, to 4.5 $\mathrm{MPa}$ at the pile tip level for medium dense sand and 5.6 MPa for the dense sand. Based on the considerations made by Yang et al. (2010), no significant crushing is expected, and localization of strains in the shear band along the piles seems to have been the preponderant process.

In order to account for the fact that, when driven model piles are installed and loaded, a shear band along the pile-sand interface develops, as observed by Arshad et al. (2014) in cone tests, two different soil modulus profiles were considered to calculate interaction factors between piles. These profiles are shown in Figure 12: for profile $1, E_{s}$ increases linearly with depth up to $E_{s-t i p}$ at the depth of the pile base, while for profile $2, E_{S}$ increases linearly with depth at a smaller rate until the base of the pile is reached and, at the depth corresponding to the base of the pile, the value of the modulus is $E_{s-t i p}\left(E_{s-t i p}\right.$ is the soil modulus at the base of the pile obtained from profile 1). The second idealised soil profile attempts to capture the effects of shear localization by reducing the value of modulus along the shaft. Figure 13 compares the interaction factors calculated for both soil profiles us- 


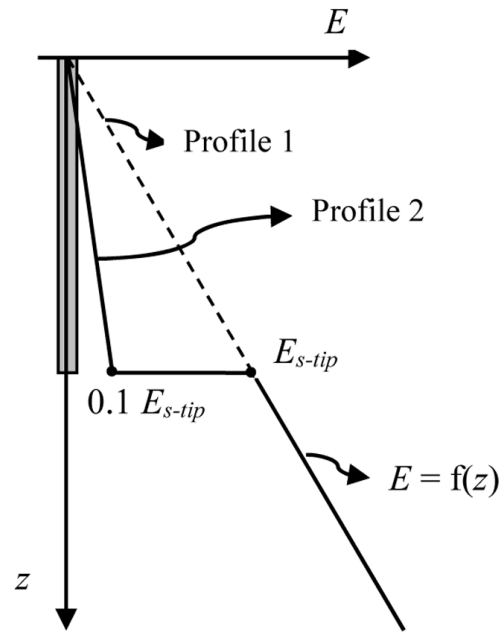

Fig. 12. Two different profiles assumed for the soil elastic modulus: linear profile versus profile with reduced soil modulus along the pile shaft

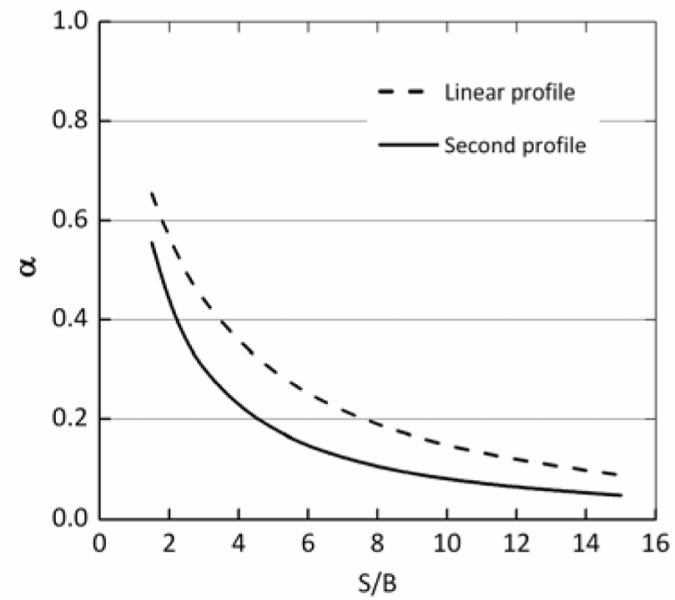

Fig. 13. Interaction factor calculated for the two different soil profiles presented in Figure 12

ing the software DEFPIG (Poulos 1990) for the medium dense sand sample.

\subsection{Prediction of model pile group response}

All the test results were compared with predictions obtained using both the idealised soil modulus profiles shown in Figure 12. The predicted load-settlement response of the pile groups was quite similar for these two soil modulus profiles considered. This can be explained by considering that most of the settlement of any pile in a small group results from the first term in Eqn (8), which accounts for pile stiffness degradation, with limited contribution from the induced elastic settlement of neighboring piles, calculated from the second term in Eqn (8). However, this may not and likely is not true for larger pile groups of driven or jacked piles in sand. Only the soil modulus profiles presented as soil profile 2 in Figure 12 were used to produce the results of the analyses discussed next.
Figure 14 presents the results for model pile group tests performed in loose sand ( $D_{R}$ of $38 \%$ and with centerto-center spacing of $3 B$ ) and the predicted response using a nonlinear pile load-settlement response back-calculated from the single pile tests, as discussed previously. The predictions shown in Figure 14 go only up to the ultimate model pile capacity (that corresponding to $w=10 \% B$ ) since this is the load used as reference in pile design (this was the maximum capacity provided as input in GARP).

(a)

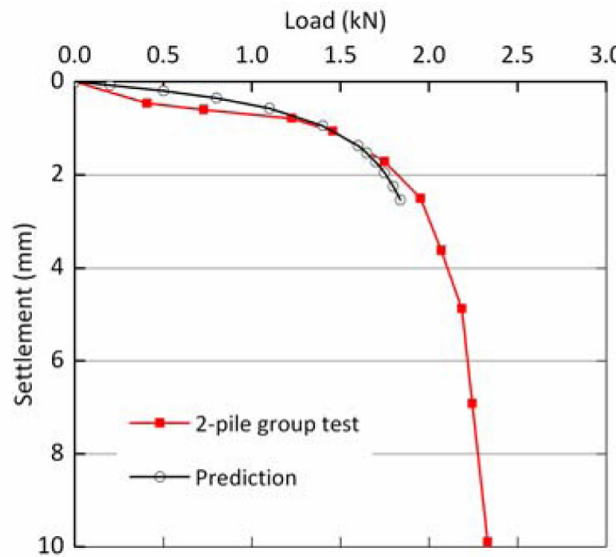

(b)

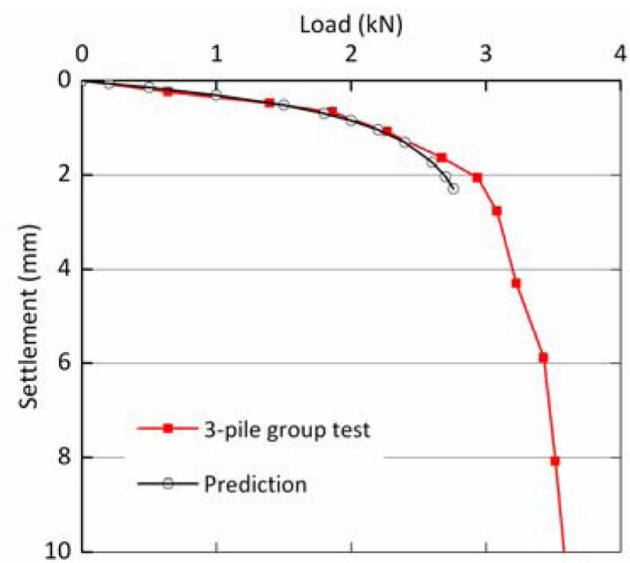

(c)

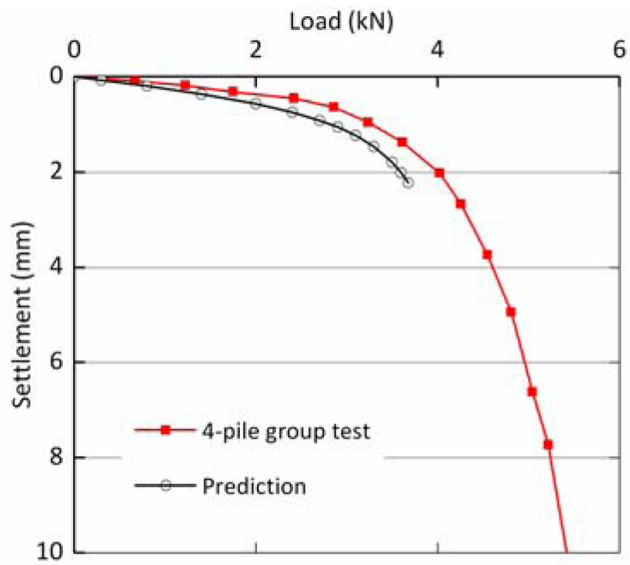

Fig. 14. Comparison of measured and predicted pile group response in loose sand $(S / B=3)$ : (a) 2-pile group; (b) 3-pile group; (c) 4-pile group 


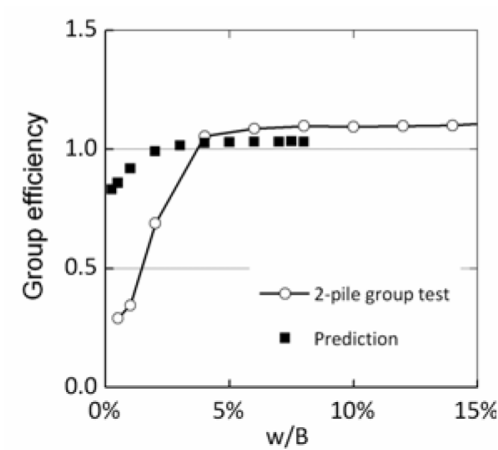

(a)

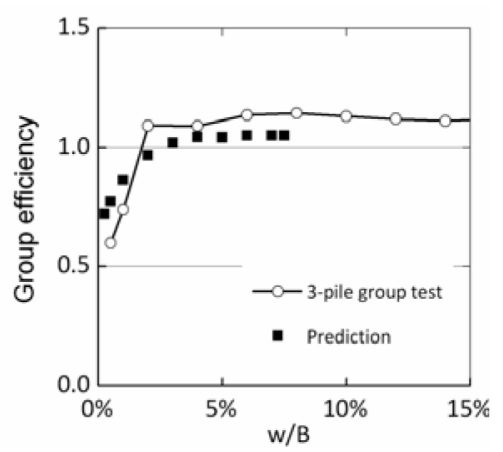

(b)

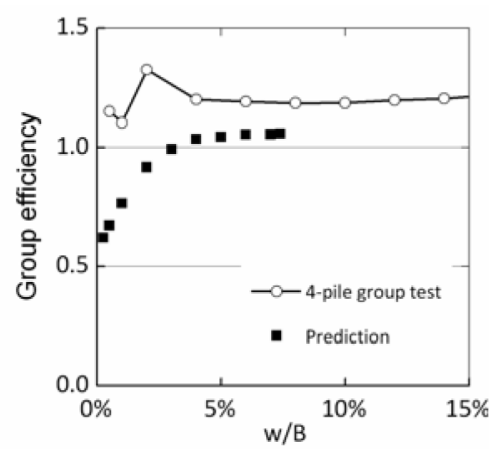

(c)

Fig. 15. Comparison of group efficiency calculated for measured and predicted pile group response in loose sand $(S / B=3)$ : (a) 2-pile group; (b) 3-pile group; (c) 4-pile group

The predicted and measured load-settlement curves are in very good agreement for the 2- and 3-pile group tests. However, as can be seen in Figure 14c, a slight underprediction is observed for the 4-pile group, which may be related to the increase in pile capacity resulting from sand densification during driving in loose sand. Since the parameters used in the prediction of pile group response are determined from single pile response, it is likely that underprediction will increase with the addition of more piles to the group, if the piles are displacement rather than nondisplacement piles.

Figure 15 compares the group efficiency, for different settlement levels, of model pile group tests performed in loose sands and the group efficiency based on predicted values for pile group and single pile. All values were obtained using Eqn (3). The agreement between the prediction and experimental results is good, showing a stabilization trend after a settlement of approximately $4 \%$ of $B$.

Figure 16 compares the predictions and the results of the tests performed in medium dense sand $\left(D_{R}=59 \%\right)$. In a similar way as in loose sands, the 2- and 3-pile group test results (Figs 16a and 16b) and the respective predictions are in very good agreement. For the 4-pile group test (Fig. 16c), the experimental results show a stiffer response and also a higher ultimate capacity than the predictions. Figure 17 shows the values of group efficiency calculated for the measured and predicted results, as described before. All the values of group efficiency are above 1 for the three group configurations, and the predicted and measured results are in reasonable agreement for settlements over $6 \% \mathrm{~B}$ for the 2- and 3-pile groups. The 4-pile group tests for medium dense sand (Fig. 17c) and also for loose sand (Fig. 15c) have efficiency greater than 1 during the entire tests, indicating that the sand densification process was more intense for this pile group configuration.

Figures 18 and 19 present predictions for pile-load response and group efficiency, respectively, for 2-, 3-, and 4-pile group tests performed in dense sands samples. The tests for 2- and 3-pile groups showed very good agreement in the initial part of the load-settlement curve (a)

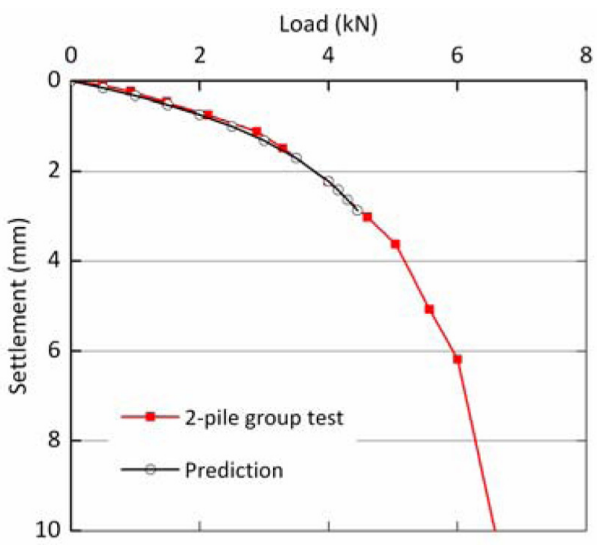

(b)

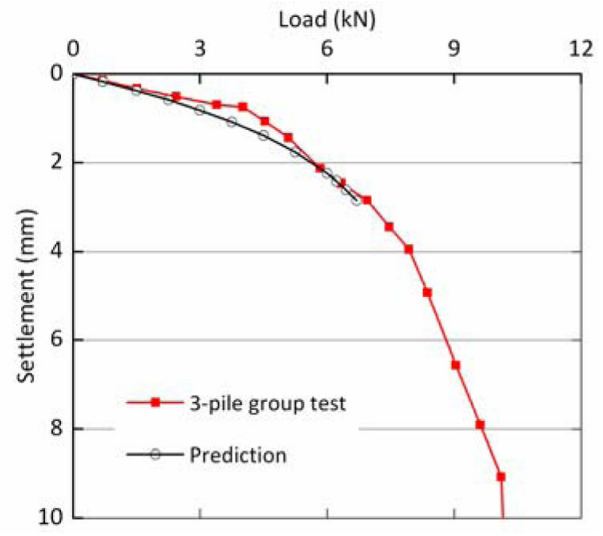

(c)

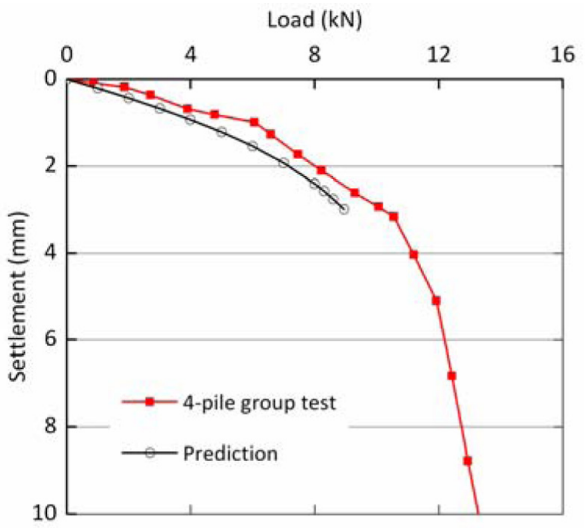

Fig. 16. Comparison of measured and predicted pile group response in medium dense sand $(S / B=3)$ : (a) 2-pile group; (b) 3-pile group; (c) 4-pile group 


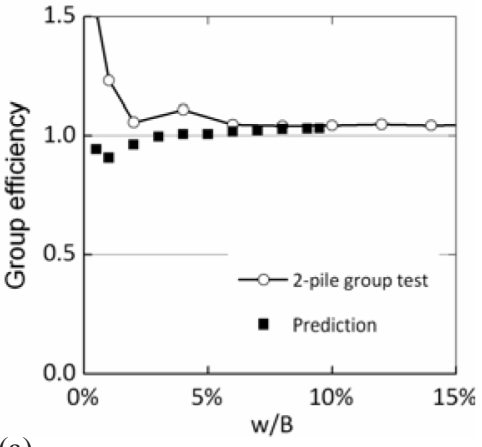

(a)

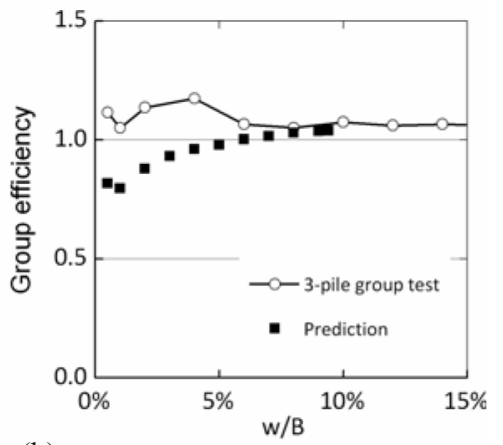

(b)

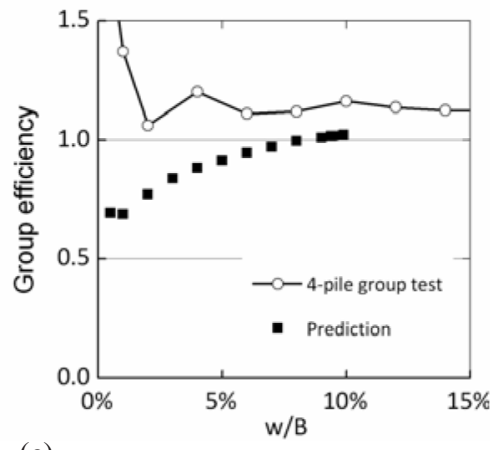

(c)

Fig. 17. Comparison of group efficiency calculated for measured and predicted pile group response in medium dense sand $(S / B=3)$ : (a) 2-pile group; (b) 3-pile group; (c) 4-pile group

(a)

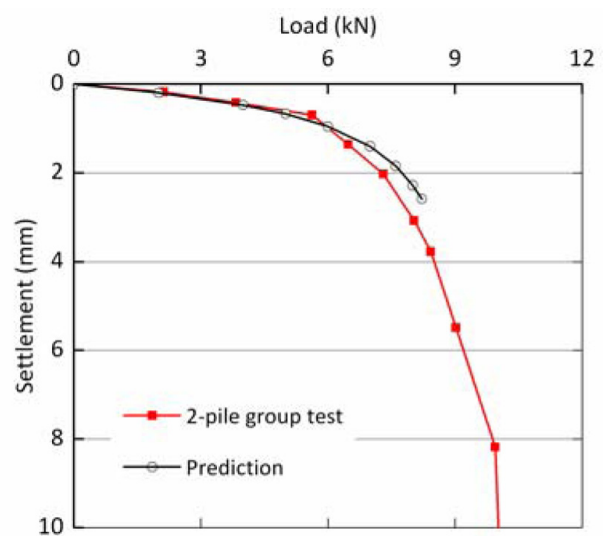

(b)

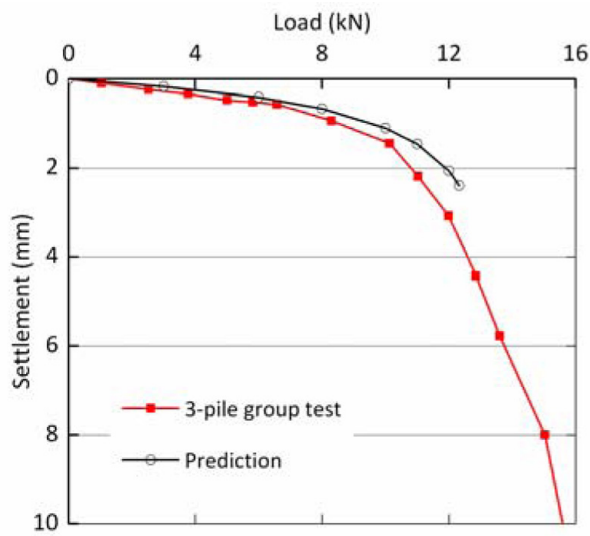

(c)

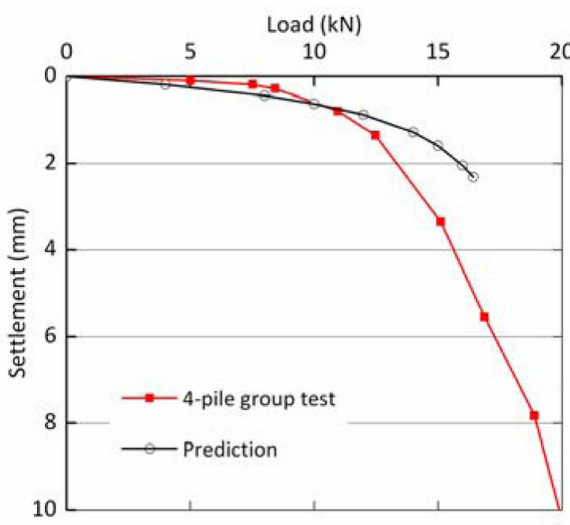

Fig. 18. Comparison of measured and predicted pile group response in dense sand $(S / B=3)$ : (a) 2-pile group;

(b) 3-pile group; (c) 4-pile group

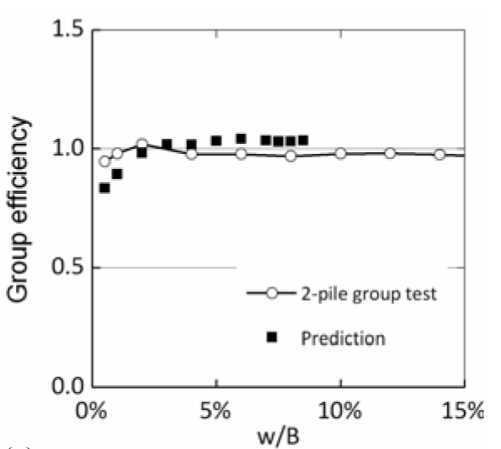

(a)

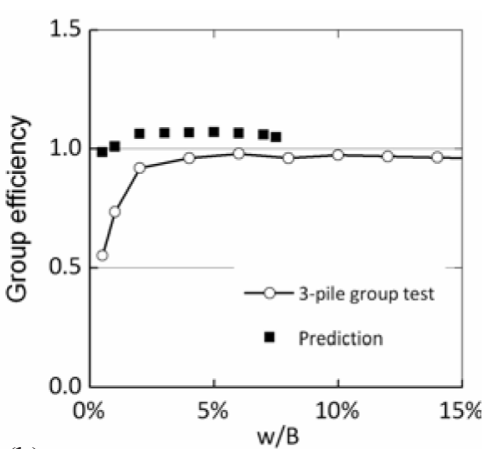

(b)

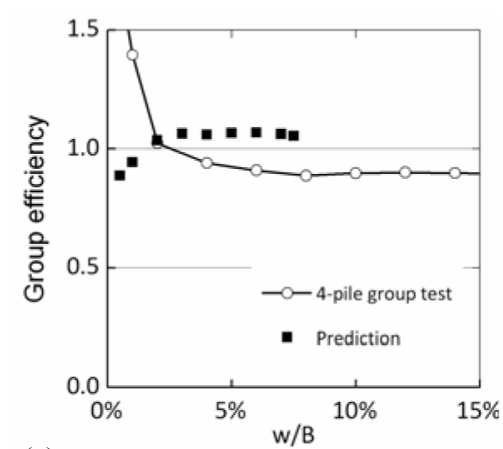

(c)

Fig. 19. Comparison of group efficiency calculated for measured and predicted pile group response in dense sand $(S / B=3)$ : (a) 2-pile group; (b) 3-pile group; (c) 4-pile group 
(a)

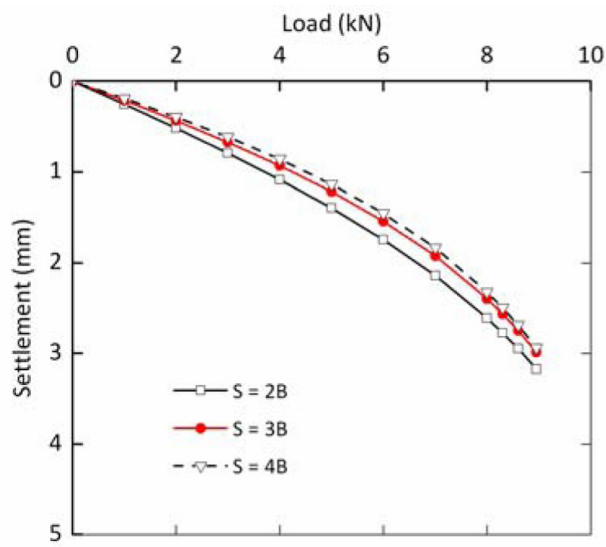

(b)

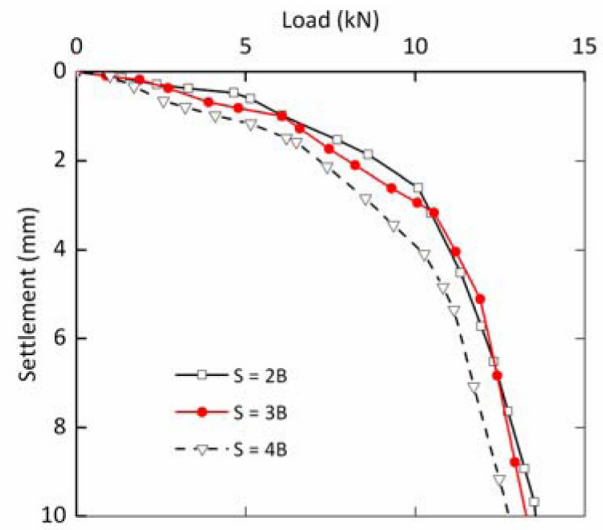

Fig. 20. Results for 4-pile group tests in medium sand with different center-to-center pile spacing: (a) Predicted loadsettlement response for 4-pile groups; (b) measured load settlement response for 4-pile group tests

(approximately the same initial stiffness), but the experimental results show lower ultimate load capacity.

Figure 20 shows the prediction and test results for three 4-model pile groups with center-to-center pile spacing equal to $2 B, 3 B$, and $4 B$. For the predictions, for which individual pile stiffness is always the same, the closer the piles, the less stiff the pile group, owing to the increase in pile interactions (Fig. 20a). However, the experimental data (Fig. 20b) showed an opposite trend,

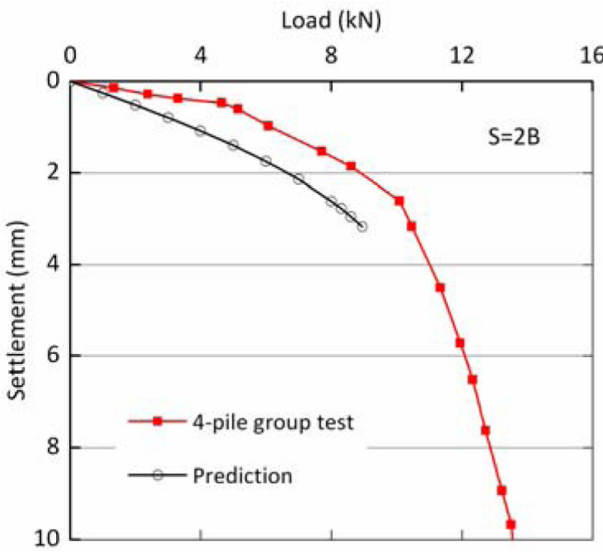

(a)

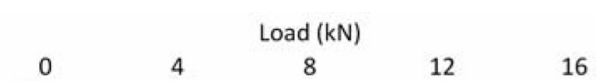

(b)

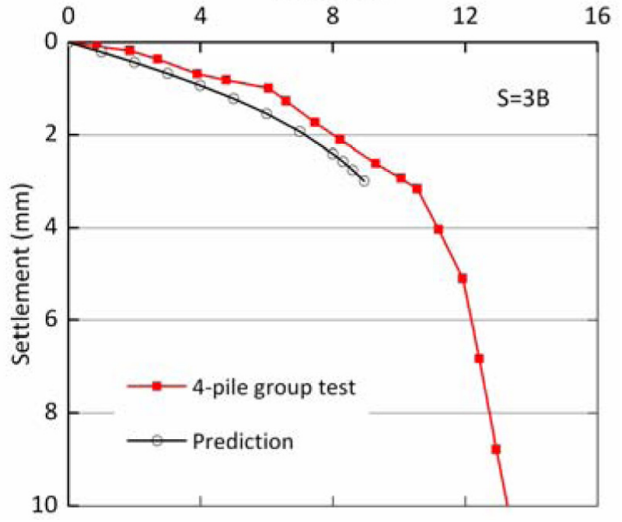

(c)

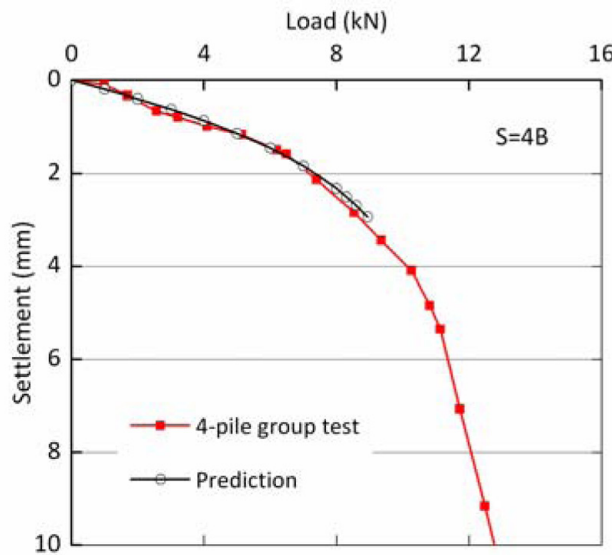

Fig. 21. Predicting 4-pile group behaviour - Groups with different pile spacing: (a) $S / B=2$; (b) $S / B=3$; (c) $S / B=4$

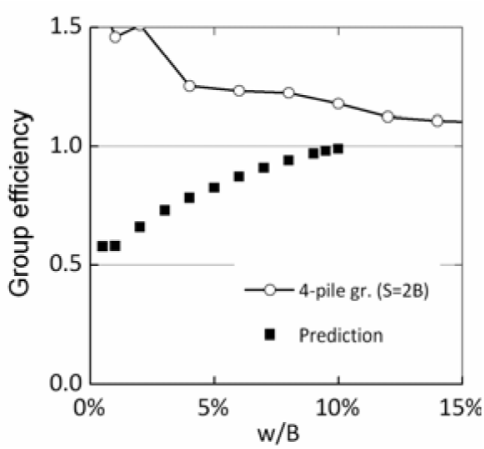

(a)

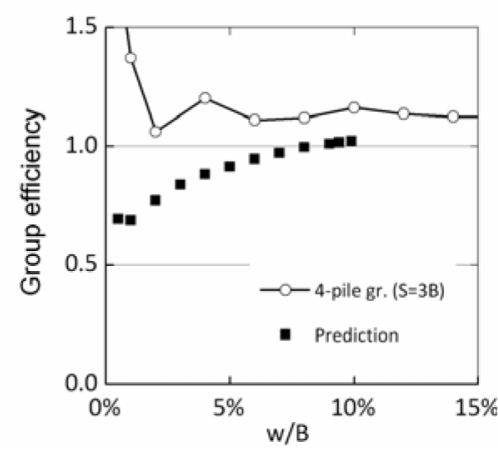

(b)

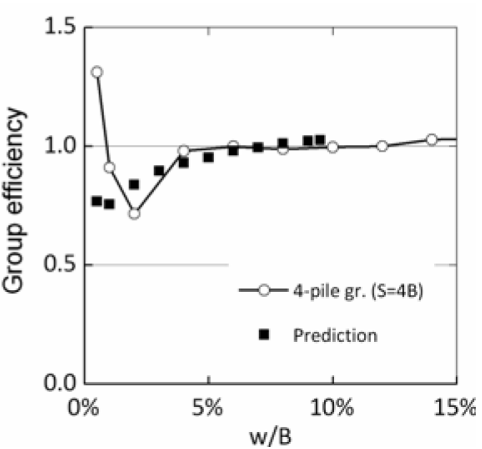

(c)

Fig. 22. Comparison of group efficiency calculated for measured and predicted pile group response in medium dense sand for different pile spacings: (a) $S / B=2$; (b) $S / B=3$; (c) $S / B=4$ 
in which a stiffer response was observed for groups with closer piles. This illustrates the effect (mostly densification) of driving piles close together.

Figure 21 compares, side by side, the test results and the respective predictions. It can be noted that, with increasing pile spacing, the predictions became more accurate; for a pile spacing of $4 B$, the agreement between prediction and measurement is very good. The same can be seen in Figure 22, which compares measured and predicted group efficiency. This means that, for the specific driving energy, pile geometry, and soil density used in the experiments, a pile spacing equal to $4 B$ was sufficient to minimise installation and interaction effects.

\section{Conclusions}

This study presented the results of 16 model pile tests performed in a large calibration chamber built to allow model pile load tests. Three different and well-controlled sand densities were used for single pile and pile group tests. The major conclusions from this study are:

1. The load-settlement response of nondisplacement and driven piles were very different, reflecting the importance of the pile installation process. The looser the sand was, the greater the differences observed in load response;

2. The load-settlement response of a single pile can be used to predict the load response of small pile groups. Thus, a fit, as proposed in the present paper, to the single pile load-settlement curve, combined with the pile group interaction factors determined by the proposed method leads to very satisfactory predictions for all the tests in loose, medium dense and dense sand;

3. The group efficiency for a specific settlement was influenced by initial sand density and number of piles in the group. The measured group efficiency at the ultimate load capacity (pile load for a settlement equal to $10 \%$ of the pile diameter) for loose-tomedium dense sand tests is greater than 1 . However, the opposite was observed for the model pile tests in dense sand.

4. Predictions using the proposed method were better for the 2- and 3-pile groups. Square, 4-pile groups showed stiffer response for pile spacings of $2 B$ and $3 B$ than predicted;

5. Tests with three different pile spacings $(2 B, 3 B$, and $4 B$ ) were performed in medium dense sands. For $2 B$ and $3 B$ spacings, driving effects had an impact on the load-settlement response of the groups. For $4 B$ spacing, installation effects were negligible. In a practical setting, the pile spacing that essentially eliminates the effects of installation on neighboring piles during loading is a function of the energy used during installation, the pile geometry, and the sand characteristics.

\section{Acknowledgements}

The authors acknowledge the financial support of CNPq, the Brazilian National Council for Scientific and Technological Development, during the stay of first author at Purdue University.

\section{References}

Aoyama, S.; Mao, W.; Goto, S.; Towhata, I. 2016. Application of advanced procedures to model tests on the subsoil behaviour under vertical loading of group pile in sand, Indian Geotechnical Journal 46(1): 64-76. https://doi.org/10.1007/s40098-015-0152-8

Arshad, M. I. 2014. Experimental study of the displacements caused by cone penetration in sand: $\mathrm{PhD}$ thesis. Purdue University. 309 p.

Arshad, M. I.; Tehrani, F. S.; Prezzi, M.; Salgado, R. 2014. Experimental study of cone penetration in silica sand using digital image correlation, Geotechnique 64(7): 551-569. https://doi.org/10.1680/geot.13.P.179

ASTM C 778-06 Standard specification for standard sand. Annual book of ASTM standards, 2006.

ASTM D 1143/D 1143M-07 Standard test methods for deep foundations under static axial compressive load. Annual book of ASTM standards, 2007.

ASTM D 4253-00 Standard test methods for maximum index density and unit weight of soils using a vibratory table. Annual book of ASTM standards, 2000.

ASTM D 4254-00 Standard test methods for minimum index density and unit weight of soils and calculation of relative density. Annual book of ASTM standards, 2000.

Bai, X.; He, W.; Jia, J.; Han, Y. 2006. Experimental study on the interaction mechanism of cap-pile group-soil, Marine Georesources \& Geotechnology 24(3): 173-182. https://doi.org/10.1080/10641190600788254

Basu, P.; Loukidis, D.; Prezzi, M.; Salgado, R. 2011. Analysis of shaft resistance of jacked piles in sands, International Journal for Numerical and Analytical Methods in Geomechanics 35(15): 1605-1635. https://doi.org/10.1002/nag.968

Caputo, V.; Viggiani, C. 1984. Pile foundation analysis: a simple approach to non linearity effects, Rivista Italiana di Geotecnica 18(1): 32-51.

Choi, Y. S. 2012. Investigation of the response of pile groups subjected to combined loads: $\mathrm{PhD}$ thesis. Purdue University.

Choi, Y. S.; Lee, J.; Prezzi, M.; Salgado, R. 2017. Response of pile groups driven in sand subjected to combined loads, Geotechnical and Geological Engineering 35(4): 15871604. https://doi.org/10.1007/s10706-017-0194-z

Conte, G.; Mandolini, A.; Randolph, M. F. 2003. Centrifuge modeling to investigate the performance of piled rafts, in Proceedings of the $4^{\text {th }}$ International Seminar on Deep Foundations on Bored and Auger Piles, 2003, Millpress, Rotterdam, 359-366.

Cooke, R. W. 1986. Piled raft foundations on stiff clays: a contribution to design philosophy, Géotechnique 36(2): 169203. https://doi.org/10.1680/geot.1986.36.2.169

Dai, G.; Salgado, R.; Gong, W.; Zhang, Y. 2012. Load tests on full-scale bored pile groups, Canadian Geotechnical Journal 49(11): 1293-1308. https://doi.org/10.1139/t2012-087

El-Sharnouby, B.; Novak, M. 1990. Stiffness constants and interaction factors for vertical response of pile groups, Canadian Geotechnical Journal 27(6): 813-822. https://doi.org/10.1139/t90-094

Garg, K. G. 1979. Bored pile groups under vertical load in sands, Journal of Geotechnical and Geoenvironmental Engineering 105(8): 939-956. 
Horikoshi, K.; Randolph, M. F. 1996. Centrifuge modelling of piled raft foundations on clay, Géotechnique 46(4): 741752. https://doi.org/10.1680/geot.1996.46.4.741

Jardine, R. J.; Zhu, B. T.; Foray, P.; Yang, Z. X. 2013a. Measurement of stresses around closed-ended displacement piles in sand, Géotechnique 63(1): 1-17. https://doi.org/10.1680/geot.9.P.137

Jardine, R. J.; Yang, Z. X.; Foray, P.; Zhu, B. T. 2013b. Interpretation of stress measurements made around closed-ended displacement piles in sand, Géotechnique 63(8): 613-627. https://doi.org/10.1680/geot.9.P.138

Kezdi, A. 1957. Bearing capacity of piles and pile groups, in $4^{\text {th }}$ International Conference on Soil Mechanics and Foundation Engineering, 1957, London, UK, Vol. 2, 46-51.

Lee, J. 2008. Experimental investigation of the load response of model piles in sand: $\mathrm{PhD}$ thesis. Purdue University.

Lee, J.; Prezzi, M.; Salgado, R. 2013. Influence of axial loads on the lateral capacity of instrumented steel model piles, International Journal of Pavement Research and Technology 6(2): 80-85.

https://doi.org/10.6136/ijprt.org.tw/2013.6(2).80

Lee, S. H.; Chung, C. K. 2005. An experimental study of the interaction of vertically loaded pile groups in sand, Canadian Geotechnical Journal 42(5): 1485-1494. https://doi.org/10.1139/T05-068

Liang, F. Y.; Song, Z.; Guo, W. D. 2014. Group interaction on vertically loaded piles in saturated poroelastic soil $[\mathrm{J}]$, Computers and Geotechnics 56(3): 1-10. https://doi.org/10.1016/j.compgeo.2013.10.003

Liu, J. L.; Yuan, Z. L.; Zhang, K. P. 1985. Cap-pile-soil interaction of bored pile groups, in Proceedings of the $11^{\text {th }}$ ICSMFE, 1985, San Francisco, USA, Vol. 4, 1433-1436.

Loukidis, D.; Salgado, R. 2008. Analysis of the shaft resistance of non-displacement piles in sand, Geotechnique 58(4): 283-296. https://doi.org/10.1680/geot.2008.58.4.283

Loukidis, D.; Salgado, R. 2009. Modeling sand response using two-surface plasticity, Computers and Geotechnics 36(1): 166-186. https://doi.org/10.1016/j.compgeo.2008.02.009

Mandolini, A.; Viggiani, C. 1997. Settlement of piled foundations, Géotechnique 47(3): 791-816. https://doi.org/10.1680/geot.1997.47.4.791

Millan, A. A.; Townsend, F. C.; Bloomquist, D. 1987. Capacidad de grupos de pilotes em arena usando modelos centrifugados, in Proceedings of the $8^{\text {th }}$ Conference Panamericana de Suelos No Saturados PanAm-, 317-331.

Mylonakis, G.; Gazetas, G. 1998. Settlement and additional internal forces of grouped piles in layered soil, Géotechnique 48(1): 55-72. https://doi.org/10.1680/geot.1998.48.1.55

Nguyen, D. D. C.; Kim, D. S.; Jo, S. B. 2013. Settlement of piled rafts with different pile arrangement schemes via centrifuge tests, Journal of Geotechnical and Geoenvironmental Engineering 139(10): 1690-1698. https://doi.org/10.1061/(ASCE)GT.1943-5606.0000908

O’Neill, M. W. 1983. Group action in offshore piles, in Proceedings of the Specialty Conference on Geotechnical Engineering in Offshore Practice, 1983, ASCE, Houston, 25-64.

Paik, K.; Salgado, R. 2004. Effect of pile installation method on pipe pile behavior in sands, Geotechnical Testing Journal 27(1): 78-88. https://doi.org/10.1520/GTJ11268J

Parkin, A. K.; Holden, J.; Aamot, K.; Last, N.; Lunne, T. 1980. Laboratory investigations of CPT's in sand. Report 521089, NGI, Oslo.

Peterson, R. W. 1988. Laboratory investigation of the penetration resistance of fine cohesionless materials, in Proceedings of Penetration Testing, ISOPT-1, 895-901.

Poulos, H. G. 1968. Analysis of the settlement of pile groups, Géotechnique 18(4): 449-471.

https://doi.org/0.1680/geot.1968.18.4.449
Poulos, H. G. 1990. DEFPIG users manual. Centre for Geotechnical Research, University of Sydney.

Poulos, H. G. 1994. An approximate numerical analysis of pile-raft interaction, International Journal for Numerical and Analytical Methods in Geomechanics 18(2): 73-92. https://doi.org/10.1002/nag.1610180202

Poulos, H. G. 2001. Piled-raft foundation: design and applications, Géotechnique 51(2): 95-113. https://doi.org/10.1680/geot.2001.51.2.95

Poulos, H. G.; Carter, J. P.; Small, J. C. 2001. Foundations and retaining structures - Research and practice, in Proceedings of the $15^{\text {th }}$ International Conference on Soil Mechanics and Foundation Engineering, 2001, Istanbul, Turkey, Vol. 4, 2527-2606.

Randolph, M. F. 1994. Design methods for pile groups and piled rafts, in Proceedings of the $13^{\text {th }}$ International Conference on Soil Mechanics and Foundation Engineering, 1994, New Delhi, India, Vol. 5, 61-82.

Russo, G.; Abagnara, V.; Poulos, H. G.; Small, J. C. 2013. Reassessment of foundation settlements for the Burj Khalifa, Dubai, Acta Geotechnica 8: 3-15. https://doi.org/10.1007/s11440-012-0193-4

Salgado, R. 2012. The mechanics of cone penetration: Contributions from experimental and theoretical studies, in Proceedings of Geotechnical and Geophysical Site Characterization 4 (ISC-4), Keynote lecture Pernambuco, Brazil.

Salgado, R.; Mitchell, J. K.; Jamiolkowski, M. 1998. Calibration chamber size effects on penetration resistance in sand, Journal of Geotechnical and Geoenvironmental Engineering 24(9): 878-888. https://doi.org/10.1061/(ASCE)10900241(1998)124:9(878)

Salgado, R.; Han, F.; Prezzi, M. 2017. Axial resistance of nondisplacement piles and pile groups in sand, Rivista Italiana di Geotecnica. Accepted for publication.

Sales, M. M.; Small, J. C.; Poulos, H. G. 2010. Compensated piled rafts in clayey soils: behaviour, measurements, and predictions, Canadian Geotechnical Journal 47(3): $327-$ 346. https://doi.org/10.1139/T09-106

Schnaid, F.; Houlsby, G. T. 1991. An assessment of chamber size effects in the calibration of in situ tests in sand, Géotechnique 41(3): 437-445.

https://doi.org/10.1680/geotec.1991.41.3.437

Small, J. C.; Poulos, H. G. 2007. A method of analysis of piled rafts, in Proceedings of the $10^{\text {th }}$ Australia New Zealand Conference on Geomechanics, 2007, Brisbane, 550-555.

Tehrani, F. S.; Han, F.; Salgado, R.; Prezzi, M.; Tovar, R. D.; Castro, A. G. 2016. Effect of surface roughness on the shaft resistance of non-displacement piles embedded in sand, Géotechnique 66(5): 386-400. https://doi.org/10.1680/jgeot.15.P.007

Tsuha, C. H. C.; Foray, P. Y.; Jardine, R. J.; Yang, Z. X.; Silva, M.; Rimoy, S. 2012. Behaviour of displacement piles in sand under cyclic axial loading, Soils and Foundations 52(3): 393-410.

Viggiani, C.; Mandolini, A.; Russo, G. 2012. Piles and pile foundations. Spon Press. 280 p.

Vipulanandan, C.; Wong, D.; Ochoa, M.; O’Nill, M. W. 1989. Modelling of displacement piles in sand using a pressure chamber, in Proceedings of Foundation Engineering Congress, ASCE, 526-541.

Whitaker, T. 1960. Some experiments on model piled foundations in clay, in Proceedings of the $6^{\text {th }}$ Congress of International Association for Bridge and Structural Engineering, 1960, Stockholm, Sweden, 124-139.

Yang, Z. X.; Jardine, R. J.; Zhu, B. T.; Foray, P.; Tsuha, C. H. C. 2010. Sand grain crushing and interface shearing during displacement pile installation in sand, Géotechnique 60(6): 469-482. https://doi.org/10.1680/geot.2010.60.6.469 
Zhang, Q. Q.; Zhang, S. M.; Liang, F. Y.; Zhan, Q.; Xu, F. 2015. Some observations of the influence factors on the response of pile groups, KSCE Journal of Civil Engineering 19(6): 1667-1674. https://doi.org/10.1007/s12205-014-1550-7

Mauricio Martines SALES. Is a Full Professor in Civil Engineering at Federal University of Goias. He holds an undergraduate degree in Civil Engineering from the Federal University of Goias, Master of Engineering degree in geotechnical engineering from PUC-Rio (Brazil) and a PhD degree in geotechnical engineering from the University of Brasilia. Prof. Sales's interest lie in foundation engineering, in general, piled rafts behaviour, numerical methods and erosion processes.

Monica PREZZI. Is an Assistant Professor in Civil Engineering at Purdue University. She holds an undergraduate degree in civil engineering from the Federal University of Rio Grande do Sul (Brazil), Master of Engineering degree in geotechnical engineering from UFRGS, and both a Master of Science degree in geotechnical engineering and a $\mathrm{PhD}$ in civil engineering materials/geotechnical engineering from the University of California, Berkeley. She is currently doing research on analysis and design of piles and micropiles, on the effect of soil disturbance on the performance of prefabricated vertical drains, and on utilization of recyclable materials in civil engineering structures.

Rodrigo SALGADO. Is the Charles Pankow Professor in Civil Engineering at Purdue University. He holds a PhD and an MS degree from the University of California, Berkeley, and an engineering degree from the Federal University of Rio Grande do Sul (UFRGS), Brazil. Prof. Salgado's interest lie in geomechanics, computational mechanics, constitutive modeling and offshore engineering.

Yoon Seok CHOI. Is a PhD, Civil and Environmental Engineer. He holds an undergraduate degree in Civil Engineering from the Korea University, Master of Engineering degree in Civil and Environmental Engineering from Pennsylvania State University and a PhD degree in Civil Engineering from the Purdue University. His major interest lies in analysis and design of pile foundations, static and dynamic pile load tests.

Jintae LEE. Is a PhD, Civil Engineer. He holds an undergraduate and a MSc degree in Civil Engineering from the Chung-Ang University in Seoul and a PhD degree in Civil Engineering from the Purdue University. His interest lies in pile foundations, geoenvironmental problems. 